
Access article, distributed under the terms of the Creative Commons Attribution licence (http:// creativecommons.org/licenses/by/4.0/), which permits unrestricted re-use, distribution, and reproduction in any medium, provided the original work is properly cited.

doi:10.1017/bjt.2017.9

\title{
What the dogs did: animal agency in the Soviet manned space flight programme
}

\author{
AMY NELSON*
}

\begin{abstract}
This paper examines the agency of the dogs used to develop the Soviet manned space flight programme by considering what the dogs did as experimental subjects, as dog technologies, and as individual dogs in the context of the historically conditioned practices of Soviet science. Looking at how Soviet space researchers refined Pavlovian behaviourism and integrated it into a complex engineering project helps clarify the conditions under which the dogs worked and the assumptions that guided the human researchers. The paper uses theoretical perspectives that contextualize animal agency in terms of relationships and then looks at those relationships from an ethological perspective. This provides a sense of what the dogs did that distinguishes between how humans understand dogs and what we know about dogs' cognitive and social capacities. The paper proposes a model of animal agency that looks seriously at the dogs' relationships with human researchers and suggests that the dogs' significance as historical subjects depends as much on what they did as dogs as it does on how their contributions to the space race were perceived.
\end{abstract}

Among the legions of animals used in scientific research few have garnered the fame of the Soviet space dogs. While the vast majority of experimental organisms live and die in anonymity, the names of many of the diminutive canines who helped develop the Soviet manned space flight programme were known around the world: Laika ('Barker'), the first living being to orbit the earth; Belka and Strelka ('Fox' and 'Arrow'), the first to return alive after orbital flight; and Zvezdochka ('Little Star'), the final dog to fly before Yuri Gagarin became the first man in space. Their fame as individuals makes their claim for historical significance fairly straightforward. On both sides of the superpower divide, researchers, politicians and the general public perceived them as pioneers and scouts. The dogs' ability to survive in space provided a clear bridge to the advent of human space travel, a connection made stronger by the long and intertwined histories of humans and the oldest domesticate.

* Department of History (0117), Major Williams Hall, Virginia Tech, 220 Stanger Street, Blacksburg, VA 24061, USA. Email: anelson@vt.edu.

The College of Liberal Arts and Human Sciences at Virginia Tech and the Summer Research Laboratory on Russia and Eastern Europe at the University of Illinois supported the research for this article. Publication costs were offset by the Open Access Subvention Fund at Virginia Tech. The Humane Society of the United States provided a haven in which to think and write via the Shin Pond Summer Retreat Program. I am grateful to the outside reviewers for their trenchant comments and to Amanda Rees for her timely encouragement, compassionate professionalism and scintillating humour. 
I have written elsewhere about how celebrity helped the space dogs function as 'boundary objects' to global communities. ${ }^{1}$ They meant different things to different human audiences who saw them in often contradictory ways - as experimental animals, brave scouts, hapless victims or stellar exemplars of the family pet. The concept of 'dog' underpinned this multifaceted resonance, providing an interface ('translation') between the otherwise divergent social worlds of engineers, scientists, politicians and the general public. ${ }^{2}$ This kind of subjectivity born of significance supports broader efforts to appreciate how integral non-human animals are to a social fabric we tend to see in exclusively human terms.

Here I want to bracket what the dogs meant and look more carefully at what they did as experimental subjects, as dog technologies and, most importantly, as individual dogs in the context of the historically conditioned practices of Soviet science. Those practices were both materialist and anthropomorphic, and they assumed a continuity and even similarity between dogs and people. Looking at how Soviet science in the 1950s refined Pavlovian behaviourism and integrated it into a complex engineering project helps clarify the conditions under which the dogs worked and the assumptions that guided the human researchers. Considering the interactions between people and dogs from the perspective of theoretical frameworks that contextualize animal agency in terms of relationships and interaction and then looking at those relationships from an ethological perspective might provide a sense of what the dogs did that distinguishes between how humans understand dogs and what we know about dogs' cognitive and social capacities. ${ }^{3}$ The goal of this paper is to develop a model of animal agency that looks seriously at the dogs' relationships with human researchers and suggests that the dogs' significance as historical subjects depends as much on what they did as dogs as it does on how their contributions to the space race were perceived. Following a basic premise of actor-network theory (ANT), my analysis proceeds from an understanding of agency that distributes the capacity to influence the course of events among humans and non-humans. ${ }^{4}$ It also supports Chris Pearson's claim that 'animal agency

1 Amy Nelson, 'Cold War celebrity and the courageous canine scout: the life and times of the Soviet space dogs', in James T. Andrews and Asif Siddiqi (eds.), Into the Cosmos: A Cultural History of the Soviet Space Age, Pittsburgh: University of Pittsburgh Press, 2011, pp. 133-155.

2 On the sociological concept of boundary objects see S.L. Star and J.R. Griesemer, 'Institutional ecology, "translations" and boundary objects: amateurs and professionals in Berkeley's Museum of Vertebrate Zoology', Social Studies of Science (1989) 19, pp. 387-420.

3 Approaches to agency that highlight the constitutive role of relationships and human-animal interaction include Vinciane Despret, 'The body we care for: figures of anthropo-zoo-genesis', Body \& Society (2004) 10, pp. 111-34; Donna J. Haraway, The Companion Species Manifesto: Dogs, People, and Significant Otherness, Chicago: Prickly Paradigm Press, 2003; and Haraway, When Species Meet, Minneapolis: University of Minnesota Press, 2007. Ethological studies relevant to this discussion include Alexandra Horowitz, Inside of a Dog: What Dogs See, Smell, and Know, New York: Scribner, 2010; Ádám Miklósi, Dog Behaviour, Evolution, and Cognition, Oxford: Oxford University Press, 2008; and Patricia B. McConnell, The Other End of the Leash: Why We Do What We Do around Dogs, reprint edn, New York: Ballantine Books, 2003.

4 Bruno Latour, Reassembling the Social: An Introduction to Actor-Network Theory, Oxford: Oxford University Press, 2007; Colin Barron (ed.), 'A strong distinction between humans and non-humans is no longer required for research purposes: a debate between Bruno Latour and Steve Fuller', History of the Human Sciences (2003) 16, pp. 77-99. 
is often entangled with human agency in reciprocal and hybrid ways' by looking at the species-specific expectations and communication strategies of dogs and people in a laboratory setting. 5

In her analysis of Robert Rosenthal's work on experimenter effects, Vinciane Despret examines the complicated links between beliefs, affects and bodies and shows how interactions between humans and animals in scientific research can constitute practices of domestication that construct humans and animals. ${ }^{6}$ Turning traditional interpretations of experimenter effects and definitions of science on their heads, Despret suggests that researchers' beliefs about experimental organisms shape their interactions with those animals. Even more powerfully, she proposes that those beliefs support the creation of new identities for the researchers and the animals. This process of anthropo-zoogenesis shows how bodies that are attuned to each other actively contribute to science as a process of 'creating a becoming' rather than of revealing a pre-existing reality. ${ }^{7}$

In the case of the space dogs, the researchers' belief that space flight was possible animated their expectations of what the dogs could do and their commitment to developing the equipment and systems that would take them beyond the Earth's atmosphere and return them safely. Furthermore, human assumptions about the nature of dogs about what was going on in their minds and what their bodies did - shaped how the dogs were handled and provided a cornerstone of essential human-dog interactions in the laboratory. ${ }^{8}$ Given the long symbiotic co-evolution of humans and domestic canines, interspecies cooperation comprised a key element of that cornerstone.

Indeed, among the most striking characteristics of dogs as a species (Canis familiaris) is their preference for mixed-species groups and the complex communication and cooperation skills that make them so successful in human communities. ${ }^{9}$ Although the morphological differences between us are considerable, dogs and humans have functionally similar behavioural traits that scientists now see as artefacts of convergent evolution. ${ }^{10}$ Anthropomorphizing dogs comes naturally to us, and even permeates scientific research, although ethologists such as Alexandra Horowitz, Ádám Miklósi and Brian Hare are pursuing research that considers the unique sensory and cognitive abilities of dogs and their perceptual world. ${ }^{11}$

5 Chris Pearson, 'History and animal agencies', in Linda Kalof (ed.), The Oxford Handbook of Animal Studies, Oxford: Oxford University Press 2017, pp. 240-257, 241. I very much appreciate the outside reviewer who brought this essay to my attention.

6 Robert Rosenthal, Experimenter Effects in Behavioral Research, vol. 13, East Norwalk: AppletonCentury-Crofts, 1966; Despret, op. cit. (3).

7 Despret, op. cit. (3), p. 121

8 On the significance of species and the contract ethics that obtain between humans and dogs see Larry Carbone, What Animals Want: Expertise and Advocacy in Laboratory Animal Welfare Policy, New York: Oxford University Press, 2004, pp. 74, 82-87.

9 Miklósi, op. cit. (3), p. 15.

10 Miklósi, op. cit. (3), pp. 11-12.

11 Miklósi, op. cit. (3), pp. 16-17 (lupomorph and babymorph model equally problematic); Alexandra Horowitz and July Hecht, 'Looking at dogs: moving from anthropocentrism to canid Umwelt', in Alexandra Horowitz (ed.), Domestic Dog Cognition and Behavior: The Scientific Study of Canis Familiaris, Berlin: Springer, 2014, pp. 201-219, 201-202. 
Anthropomorphism and anthropocentrism, as well as the idiosyncrasies of Pavlovian comparative psychology, all shaped the interactions between dogs and humans in the Institute of Aviation and Space Medicine. They also informed the way that researchers wrote about and remembered the dogs they worked with. While mountains of unacknowledged inter-species communication, as well as structured and impromptu interaction, lurk beneath the surface, the complexities and contradictions of what scientists thought dogs could do, how they mattered as individuals, and how their interactions with people were constitutive leap out of this description of Lisichka ('Little Fox'), a space dog who should have been famous:

Lisichka is our favourite dog. In her we find what seems to be an unlikely combination of qualities: she is obedient, shows 'initiative' and also loves life. During experiments she behaves very attentively and actively. There is nothing unnecessary in her behaviour. For example, she never chewed at the sensors and instruments. When you first encounter all of these remarkable qualities in this animal, with its behaviour during experiments, it would seem that nature created Lisichka specially for scientific experiments. But Lisichka is only partially a creation of nature: a big role in the making [sozdanie] of experimental animals is played by the patient, loving and thoughtful attitude of the researchers in training the dogs. ${ }^{12}$

Clearly the people who worked with Lisichka regarded her as a unique individual, one who cooperated with experimenters while also displaying 'initiative' and affective states that people perceived as 'cheerful' and 'attentive'. Her suitability as an experimental organism was partly a function of her individual constitution, but that potential had been called forth and realized by the expectations and care of the investigators. Lisichka's relationships with them were consequential and specific to her. She might be considered what Donna Haraway describes as a 'significantly unfree' partner, 'whose differences and similarities to human beings, to one another, and to other organisms are crucial to the work of the lab and, indeed, are partly constructed by the work of the lab'13

The ubiquity of experimenter effects and the unacknowledged inter-species communication that shaped relationships between dogs and people make the space dog project especially well suited for a constructivist analysis of science and particular kinds of knowledge claim. ${ }^{14}$ In terms of animal agency, the physical mattered just as much as the relational: dogs' bodies made human space flight possible, and what they did (how they acted) affected the course of events. Dogs had to do many things first so that people could follow. At the most basic level, they had to endure. By doing so they helped researchers design the systems and structures that took humans beyond the Earth's atmosphere to space. But survival was not the only objective and the dogs did much more than survive. They helped confirm scientists' fears about the effects of radiation, weightlessness and the other environmental stresses on living organisms. The Soviets needed to know that humans subjected to the conditions faced by the

12 M.A. (Mariia Aleksandrovna) Gerd and N.N. (Nikolai Nikolaevich) Gurovskii, Pervye kosmonavty $i$ pervye razvedchiki kosmosa, Nauchno-Populiarnaia Seriia, Moscow: Izd-vo Akademii nauk SSSR, 1962, pp. 40-41.

13 Haraway, When Species Meet, op. cit. (3), p. 72.

14 Carbone, op. cit. (8), pp. 6-12. 
dogs would return physically and psychologically intact, and be able to reproduce - this, after all, is an important measure of evolutionary success. If the dogs did sustain physical injury or cognitive impairment, researchers needed to know if these damages were reparable and how long that healing might take. Human agency and the success of the broader effort to send people to space thus depended on and was intertwined with the agency of the dogs. This is not to suggest that dogs understood or shared the researchers' goals, but it seems safe to assume that the dogs wanted to survive and acted accordingly. What individual dogs did - how they coped, the choices they made and how they interacted with the researchers - made them agents.

\section{A word about our sources}

The space dogs might be the most famous experimental animals, but in addition to the challenges inherent in human efforts to make sense of animal experience, anyone attempting to write about them must also confront tangled webs of inconsistency, missing or withheld evidence and the vagaries of memory. ${ }^{15}$ These challenges reflect those plaguing Soviet space history more generally, but work in paradoxical ways to the advantage of the historian of canine agency. The Soviet regime's determination to present the space programme only in the most positive light and to control even basic information meant that the programme's history remained skeletal until the late 1980s. As the strictures of censorship relaxed with the collapse of the Soviet Union, the archives began to open and participants began to document their contributions publicly. But it was a halting and piecemeal process. Just establishing an accurate chronology of the early rocket flights that carried dogs remains challenging, and between the penchant for secrecy and the widespread practices of renaming dogs and reusing the same names on different dogs, it is still impossible to make concrete claims about exactly how many dogs flew and when. Even something as basic as the cause and date of the death of Laika, the first living being to orbit the earth, fuelled speculation and controversy until 2002, when a researcher from the Institute of Biomedical Problems revealed that she had died of overheating within the first few hours of her voyage. ${ }^{16}$

15 Accounts of the space dog programme in English include Olesya Turkina, Soviet Space Dogs, London: Fuel Publishing, 2014; Amy Nelson, 'The legacy of Laika: celebrity, sacrifice and the Soviet space dogs', in Dorothee Brantz (ed.), Beastly Natures: Animals, Humans, and the Study of History, Charlottesville: University of Virginia Press, 2010, pp. 204-224; Nelson, op. cit. (1); Asif A. Siddiqi, 'There it is! An account of the first dogs-in-space program', Quest (1996) 5(3), pp. 38-42; Colin Burgess, 'Dogs who rode in rockets', Spaceflight (1996) 38, pp. 421-423; and Colin Burgess and Chris Dubbs, Animals in Space: From Research Rockets to the Space Shuttle, Berlin: Springer, 2007, pp. 61-84, 143-165, 213-218. Also see the documentary film directed by Oleg Gazenko's son for the BBC: Roman Gazenko, Space Dogs, BBC Four Television, 6 July 2009.

16 D.C. Malashenkov, 'Some unknown pages of the living organisms' first orbital flight', paper presented at 34th COSPAR Scientific Assembly, the Second World Space Congress, Houston, Texas, 10-19 October 2002, at http://adsabs.harvard.edu/abs/2002iaf..confE.288M. Aleksandr Seriapin commented on the uncertainty about when Laika died and the consternation her premature death provoked within the space programme in Aleksandr Dobrovol'skii, 'Kosmicheskaia odisseia: 32 khvostatykh kosmonavta', Moskovskii komsomolets (12 April 2004) 79, p. 8. 
We know that the lives and experiences of the dogs were extensively documented that they each had a 'passport' (complete with photograph), and that their biological processes (heartbeat, respiration and so on) and reaction to experimental situations were carefully recorded, as was what they ate, how they slept, what they did in their kennels, how they behaved on walks and how they interacted with other dogs and people. ${ }^{17}$ Gaining access to these records, however, has not been possible. This is partly due to the renewed suspicion of foreign researchers working in Russian archives. It also reflects the fragmented and constantly evolving administrative structure of the Soviet space programme, which pitted government agencies, the military, design firms and individuals against each other. Among the many consequences of this ad hoc administrative structure is a contested historical legacy and memory grounded more in the memoirs and memories of the participants than in the programme's primary historical documents. ${ }^{18}$ While the mutable and subjective nature of memory presents challenges in terms of documenting the past, those same qualities make the recollections of the physicians and technicians who worked with the dogs immensely valuable for the testimony they offer about how these people thought about, interacted with, and remembered the dogs in their care. Reflective sources such as memoirs and interviews offer important perspective on why people behaved the way they did, on how the dogs responded to them, and on the significant relationships that developed between particular dogs and particular people. ${ }^{19}$

Technical publications about the dog programme began to appear in print after Laika's voyage and became more numerous after Gagarin's historic flight in April

17 V.I. (Vladimir Ivanovich) Yazdovskii, Na tropakh vselennoi: Vklad kosmicheskoi biologii i meditsiny $v$ osvoenie kosmicheskogo prostranstva, Moscow: Firma 'Slovo', 1996, pp. 33-36; M.A. (Mariia Aleksandrovna) Gerd and N.N. (Nikolai Nikolaevich) Gurovskii, The First Astronauts and the First Scouts in Outer Space, Wright-Patterson Air Force Base, Ohio: Foreign Technology Division, Air Force Systems Command, 1963, p. 147.

18 Slava Gerovitch, Soviet Space Mythologies: Public Images, Private Memories, and the Making of a Cultural Identity, Pittsburgh: University of Pittsburgh Press, 2015. There is, of course, a vast literature on the history of the Soviet space programme. The definitive study based on Russian sources that became available after the Cold War remains Asif Siddiqi's Challenge to Apollo: The Soviet Union and the Space Race, 1945-1974, Washington, DC: NASA, 2000.

19 Key participants' memoirs include Yazdovskii, op. cit. (17). Excerpts from Yazdovskii's memoirs are included in Iu. A. Mozzhorin et al. (eds.), Dorogi $v$ kosmos: Vospominaniia veteranov raketnokosmicheskoi tekhniki i kosmonavtiki, 2 vols., Moscow: Izdatel'stvo MAI, 1992, vol. 2, pp. 119-151; and in English translation in Peter Berlin, Roads to Space: An Oral History of the Soviet Space Program, New York: Aviation Week Group, 1995, pp. 215-234. Also see Aleksei Ivanov, Pervye stupeni: Zapiski inzhenera, 2nd edn, Moscow: Molodaia gvardiia, 1975; Ivan Kas'ian, 'My, kosmicheskie mediki', in V.K. Chanturiia (ed.), ... Tri, dva, odin!, Moscow: Sovetskaia Rossiia, 1989, 257-298; A.I. Ostashev and Elena Iur'evna Bashilova, comp., 'Prelestnaia, spokoinaia Laika byla slavnoi sobakoi: k 45-letiiu so dnia zapuska vtorogo ISZ', Istoricheskii arkhiv (2002) 6, pp. 11-18; Ekaterina Puchigina, 'Klubnye stranitsy: Sukiny deti s orbity', Moskovskii komsomolets (12 April 2001) 3; and P. Sharov, 'Dorogoi v kosmos liudiam prolozhili sobaki', Novosti Kosmonavtiki (2009) 19, pp. 64-69. Cathleen Lewis's interview with Oleg Gazenko conducted at the Institute of Biomedical Problems in 1989 is also essential: Smithsonian Institution Archives, Record Unit 9551, Soviet Space Medicine Interviews, at http://sova.si.edu/record/ Record\%20Unit\%209551. 
1961. ${ }^{20}$ While these studies are useful despite their opaqueness and even silence in many areas, popular-science accounts written by the key figures in the programme (albeit under pseudonyms) offer a wealth of relevant detail. Intended for a broad audience and designed to mobilize enthusiasm for the space flight programme, books such as The First Cosmonauts and First Scouts of Space abandoned the detached tone and arcane terminology of studies for specialists in favour of more accessible accounts of how dogs fit into the multidisciplinary team of engineers, physicians and technicians who developed the space programme. They offer a wealth of evidence about what the dogs did, what was done to them, what researchers thought about the dogs, and how those accounts connect to common perceptions of what dogs are and how they fit in human society. ${ }^{21}$ Read 'against the grain', as Erika Fudge (invoking Walter Benjamin) suggests historians of animals approach the necessarily anthropocentric texts that document our past, and with an eye to ethological perspectives on how dogs make their way in the world, these sources have much to say about the relationships and experiences shared by humans and dogs that made human space flight possible. ${ }^{22}$

\section{Rocket dogs to space dogs}

The Soviets' work with dogs began when plans to use the innovations in rocketry that emerged from the Second World War for space flight were in their formative stages. Sergei Korolov enlisted Vladimir Yazdovskii, a veteran surgeon and army doctor, to develop a biological programme for space research at the Institute for Aviation Medicine in Moscow in 1948. While the institute had useful expertise in aviation medicine, which focused on how hypoxia, excessive $\mathrm{g}$ forces and extreme temperatures affected living organisms (especially pilots), space biology would need to take additional conditions into account, including the physiological effects of prolonged weightlessness, the potential damages caused by cosmic radiation, and the need to survive for extended periods in closed ecological systems. ${ }^{23}$ The means for protecting organisms from the environmental dangers of space flight, and the technology for gathering data about physiological processes (heartbeat and so on) and for providing life support during

20 V.N. Chernov and V.I. Yakovlev, 'Research on animal flight in an artificial earth satellite', Iskusstvenye sputniki zemli (English) (1960) 1, pp. 102-120; Akademiia nauk SSSR, Otdelenie fiziologii, and Otdelenie biologicheskikh nauk, Problemy kosmicheskoi biologii, Moscow: Izd-vo 'Nauka', 1962. English translation: United States and National Aeronautics and Space Administration, Problems of Space Biology, NASA Technical Translation, Washington, DC: National Aeronautics and Space Administration, 1969. V.I. (Vladimir Ivanovich) Yazdovskii, Biologiia i kosmos: Problemy kosmicheskoi biologii i meditsiny, Novoe $\mathrm{v}$ zhizni, nauke, tekhnike. VIII Seriia, Biologiia i meditsina, 1964, 1-2, Moscow: Znanie, 1964.

21 M.A. Gerd and N.N. Gurovskii, Pervye kosmonavty i pervye razvedchiki kosmosa English translation: Gerd and Gurovskii, op. cit. (17). A second, expanded, edition of this book published in 1965 includes additional chapters on space medicine for human cosmonauts. Also see O. Gorlov and V. Borisov, Zhivotnye v kosmose, Moscow: Znanie, 1960; and V. Borisov and O. Gorlov, Zhizn' i kosmos, Moscow: Sovetskaia Rossiia, 1961. English translation: O. Gorlov and V. Borisov, Life and Space, Wright-Patterson Air Force Base, Ohio: Translation Division, Foreign Technology Division, 1964.

22 Erica Fudge, 'A left-handed blow: writing the history of animals', in Nigel Rothfels (ed.), Representing Animals, Bloomington: Indiana University Press, 2002, pp. 3-18.

23 Peder Anker, 'The ecological colonization of space', Environmental History (2005) 10, pp. $239-268$. 
space travel, would be developed in tandem with the research on experimental organisms. Yazdovskii's team began experiments imitating different conditions of space flight in the laboratory and also planned for experiments under the actual conditions of rocket flight. ${ }^{24}$

Yazdovskii's team, which initially included Aleksandr Seriapin (an MD tasked with developing life-support systems, including the first space suits) and the physiologist Vitalii Popov, drew up a daunting list of requirements for the subjects of the experiments: they needed animals that could endure the stresses of space flight, and whose response to environmental adversity could be compared to that of humans. The animals would have to spend long periods of time restrained in a small, enclosed space while wearing special clothing and monitors. They also needed to be easy to train, monitor and care for. ${ }^{25}$ As Yazdovskii later recalled, 'We selected dogs as biological objects because their physiology is very well studied, they adapt well to training, and are very communicative and social [kontaktny] with people.' ${ }^{26}$ The team acquired a raft of strays from the streets of Moscow, selecting dozens of healthy young adults by weight (six to seven kilograms maximum), and for light coat color (which would facilitate filming during flight). Researchers sought out mixed-breed dogs because of their hardy constitutions. Although the Americans used rats, monkeys and later chimpanzees, the Soviets considered simians unsuitable because they were highly strung, easily stressed and much less resilient than stray dogs. ${ }^{27}$ Seriapin recalled that the Americans found that working with monkeys was time-consuming and yielded mixed results, since the animals frequently tore out monitors and had to be anesthetized for flight. ${ }^{28}$

Dogs were thus critical to the multistage, multifaceted development of equipment and life-support systems. Between 1951 and 1958 there were at least twenty-nine vertical rocket launchings with canine payloads. The initial series of flights achieved an altitude of 110 kilometres, with the dogs experiencing about four minutes of weightlessness. A second series went nearly twice as high, up to 212 kilometres, and rockets in the final series achieved more than double that altitude, rising to 450 kilometres above the Earth and subjecting their passengers to ten minutes of weightlessness. Dogs in the first and third test series flew in a hermetic chamber, while a ventilated suit provided oxygen and temperature control for passengers in the second series. Recovering the canine payload safely proved to be one of the most significant challenges, as engineers experimented with different combinations of catapulting sleds and parachutes to ensure that the dogs survived on landing. Flights carried two dogs in order to have

24 Yazdovskii, op. cit. (17), p. 33.

25 Yazdovskii, op. cit. (17), pp. 33-34.

26 Mozzhorin et al., op. cit. (19), vol. 2, pp. 124-125.

27 On the Americans' preference for animals 'closer to man' versus the Soviets' choice of dogs see Clyde R. Bergwin and William T. Coleman, Animal Astronauts: They Opened the Way to the Stars, Englewood Cliffs: Prentice Hall, 1963, pp. 57-69; Burgess and Dubbs, op. cit. (15), pp. 39-40, 63, 189-190, 239-271; I. Strel'chuk and N. Gartsshtein, 'Chertveronogie pomoshchniki uchenykh', Krasnaia zvezda, 27 August 1960, p. 3; Borisov and Gorlov Zhizn' i kosmos, op. cit. (21), pp. 136-139.

28 Sharov in Mozzhorin et al., op. cit. (19), p. 65. 
comparative data on how individuals responded. For some flights the dogs were ejected at different altitudes.

When another veteran army doctor, Oleg Gazenko, joined the institute in 1955, work preparing dogs for orbital flights began. Gazenko had studied at the Military Medical Academy in a department headed by Leon Orbeli, a distinguished protégé of Ivan Pavlov. While Pavlov's practices and the vast amount that Soviets knew about dogs thanks to him would be important, Gazenko noted that the objectives of the space dog programme differed from those of physiology laboratories: 'Physiologists focus on the body, while we are interested in the creature [sushchestvo] itself. So we observed their behaviour, and perhaps learned the principles we used later in the selection and training of the cosmonauts.' 29 Because much of the work with the dogs would involve teaching them to adapt to strange and difficult situations (i.e. extensive confinement), he also enlisted the help of Maria Gerd (Gertz), who came to the institute from the celebrated circus founded by the animal trainer Vladimir Durov. ${ }^{30}$ Durov had perfected non-violent training methods that took advantage of a species' specific behaviours to choreograph elaborate multi-species spectacles that thrilled audiences. ${ }^{31}$ Before the Revolution, he had also worked with Vladimir Bekhterov (one of Pavlov's rivals) on autosuggestion, hypnosis and other forms of psychic communication in humans and animals.

As with the rocket-dog cadre, the initial screening for orbital flight candidates was based on external characteristics. All of the dogs in the orbital-flight group were females, for example, because their anatomy made fitting the anti-gravity suit and sanitation equipment easier. Further selection focused on what Yazdovskii called 'essential qualities', referring to the dog's individual responses to various tests. Only those who received rankings of 'good' or 'excellent' were considered candidates for flight. ${ }^{32}$ Some dogs in the rocket-dog pool moved on to training for orbital flight, which took several more months. But the two kinds of flight required different skill sets and dogs with more quiet dispositions made better prospects for the 'satellite-dog' group. Candidates for orbital flight had to learn to eat special food from an automatic feeder and endure ten to fifteen days in an isolation chamber.

The selection and training of prospective human cosmonauts was well under way when Belka and Strelka became the first living beings to return alive from orbital flight in August 1960. Four more orbital dog flights remained before Gagarin's historic voyage. The first of two ill-fated launches that December ended in death for the dogs Pchelka and Mushka when their capsule went off course and ground control activated its auto-destruct mechanism. An error in the trajectory of the second flight caused it to crash near the Tungus meteor crater in Siberia. This time the dogs survived, and were found cold but alive when they were recovered two days later. Flights with Chernushka and Zvezdochka in March 1961 were test runs for Gagarin's flight, with

29 Smithsonian Institution Archives, op. cit. (19), p. 34.

30 Kas'ian, op. cit. (19), p. 271.

31 Ann Kleimola, 'A legacy of kindness: V.L. Durov's revolutionary approach to animal training', in Jane Costlow and Amy Nelson (eds.), Other Animals: Beyond the Human in Russian Culture and History, Pittsburgh: Pittsburgh University Press, 2010, pp. 164-177.

32 Yazdovskii, op. cit. (17), pp. 34-35. 
the dog sitting next to a human dummy called Ivan Ivanovich. The final canine space flight came in 1966 when Ugolek and Veterok orbited the Earth for twenty-two days on the Kosmos 110 craft.

As with humans, early space flight was dangerous and difficult for the dogs. Many died during their flights. The three launches that reached an altitude of more than 450 kilometres, for example, proved deadly to four of the six dogs involved. The two that survived (Belianka and Pestraia) sustained injuries from which they eventually recovered, although their caretakers noted physiological and behaviour changes that persisted for several months. ${ }^{33}$ Many more dogs perished in the lab as a result of injuries sustained in the centrifuge, on the vibrostand or on the acceleration sled. At least fifteen dogs flew more than once, and several flew under more than one name, making an overall calculation of the number of dogs involved in these experiments difficult. ${ }^{34}$ But it is safe to say that in the decade leading up to April 1961, the Soviets sponsored missions with passenger slots for more than seventy dogs, including twenty who were put on flights between Laika's launch in 1957 and Gagarin's successful flight nearly four years later.

\section{Pavlov's space dogs}

A key impetus behind the choice of mixed-breed dogs as proto-cosmonauts was the legacy of Ivan Pavlov, whose research on digestion, the nervous system and the biological foundations of personality had been conducted on dogs. Ivan Kasian, the physician Yazdovskii enlisted to work on life-support systems and hygiene, recalled that the physiology of the dog had been exhaustively studied by Pavlov and his pupils, and that stray dogs were especially well suited for this work because they were stable, hardy and undemanding. ${ }^{35}$

Embracing Pavlov's concept and methods of the 'chronic experiment' also came naturally to the space researchers. Pavlov saw organisms as complex machines governed by determined processes that are regulated by the nervous system. ${ }^{36}$ Those processes could best be understood by working with intact, 'normal' animals rather than via 'acute' experiments (vivisection) which caused the animal to die. By surgically modifying a dog (creating a gastric fistula that provided access to the products of the digestive tract, for example) and then allowing the animal to recover before conducting the experiment, Pavlov created an animal which he believed would produce correct (pravil'nye) scientific data. His biographer characterizes the resulting dog as both a 'technology' and a 'physiological object of study, a living, functioning, infinitely complex organism'. ${ }^{37}$ This kind of 'dog technology' exemplifies Donna Haraway's claim that ' $\mathrm{t}$ ] echnologies are always compound. They are composed of diverse agents of

33 Kas'ian, op. cit. (19), p. 267; Gerd and Gurovskii, op. cit. (21), p. 126.

34 A chronological listing of the dog flights based on archival materials is provided in I.B. Ushakov, V.S. Bednenko and E.V. Lapayev (eds.), Istoriia otechestvennoi kosmicheskoi meditsiny, Voronezh: Voronezhskii gosudarstvennyi universitet, 2001, 17.

35 Kas'ian, op. cit. (19), p. 321.

36 Daniel P. Todes, Ivan Pavlov: A Russian Life in Science, Oxford: Oxford University Press, 2014, p. 142.

37 Todes, op. cit. (36), p. 153. 
interpretations, agents of recording, and agents for directing and multiplying relational action'. 38

As with Pavlov's dogs, the space dogs' agency as 'compound technologies' necessitated significant modification of the physical dog. In order to know how the stresses of space flight would affect people, Yazdovskii and Gazenko needed to monitor the bodily functions of the dogs they were using as human stand-ins. Dogs selected for orbital flights underwent surgery to have the carotid artery rerouted to the outside of the neck inside a fold of skin. Once the wound had healed, the dogs were trained to tolerate the attachment of a blood pressure cuff to the fold. The cuff could then be connected to a monitoring system that allowed researchers to record the dog's blood pressure during ground tests and flights. Tantalum monitors were implanted to register the heart's rhythm (EKG), with wires exiting near the dog's withers to make it more difficult for them to chew them off. Carbon monitors inserted into their chests enabled researchers to assess respiration. ${ }^{39}$ Thus equipped, the surgically modified dog became an integrated part of a system designed to both protect and monitor life. The orange 'space suits' the dogs wore at press conferences looked sporty to the public, but actually served as an interface between the living organism of the dog and the life-support, monitoring and restraining systems (Figure 1). They held the monitors and lead wires in place, protected the dogs' skin, connected the dogs to the sanitation equipment and provided a means to secure them in the capsule (via D-rings sewn to the garment) (Figure 2).

In addition to blood pressure, respiration and heart rate, researchers collected and analysed an array of biological data from the dogs, including EEGs to measure brainwave activity and electromyograms to assess the functioning of nerves and muscles, as well as samples of blood, bone marrow and cerebrospinal fluid. They also monitored the animals' movements during launches or tests, initially with motion sensors attached to the dogs and film cameras mounted on the ceiling of the capsule, and later (by the time of Belka and Strelka's flight) via television. Some data were saved in recordings made on board for later analysis while others were conveyed to the ground during flight via telemetry.

Needless to say, the dogs' job on these flights was to survive, not drive. They were passengers rather than pilots. But the imperative for automating and monitoring every aspect of the pre-manned flights may have conditioned the debate that haunted the manned space programme throughout the 1960s over the appropriate relationship between automating processes and human control. ${ }^{40}$

Like Pavlov's dogs, the space dogs were certainly creatures of the laboratory. As living organisms modified by humans to serve human ends, they qualify as 'biotechnologies'. ${ }^{41}$ This metaphoric vision could be extended further to view such dog technologies as the

38 Haraway, When Species Meet, op. cit. (3), p. 250.

39 Kas'ian, op. cit. (19), p. 265; Gerd and Gurovskii, op. cit. (21), p. 61.

40 Gerovitch, op. cit. (18), pp. 48-67.

41 Edmund Russell, 'Introduction: the garden in the machine', in Susan R. Schrepfer and Philip Scranton (eds.), Industrializing Organisms: Introducing Evolutionary History, London: Routledge, 2004, pp. 1-18, 5-6; Bruno Latour, 'The costly, ghastly kitchen', in Perry Williams and Andrew Cunningham (eds.), The Laboratory Revolution in Medicine, Cambridge: Cambridge University Press, 1992, pp. 295-303, $298-299$. 


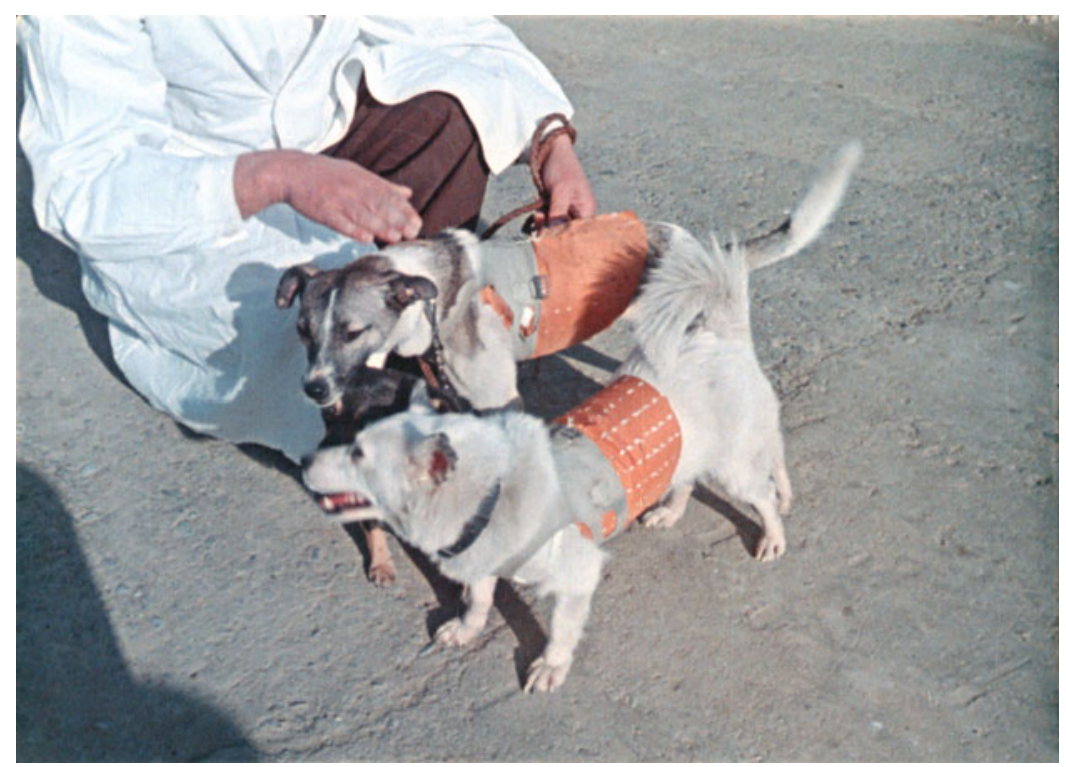

Figure 1. Laika and $\mathrm{Al}^{\prime}$ bina in their space suits (1957). Source: Rossiiskii gosudarstvennyi arkhiv nauchno-tekhnicheskoi informatsii (Russian State Archive for Scientific-Technical Documentation - RGANTD), arkh. No 0-10113cv.

'machinery' or site of manufacture in a laboratory factory. ${ }^{42}$ From the perspective of ANT, which focuses on the networked interactions of heterogeneous actors, the dogs have agency as technologies or 'human-altered objects'. But more importantly, in terms of animal agency, the space dogs' capacity to act - their ability to engage other agents (humans and technologies) in the network and to influence the course of events - is connected to conceptions of labour and work, and to their qualities as individuals. The dogs were working subjects, not working objects. And they were not interchangeable or generic.

Space researchers were quite explicit about using dogs as stand-ins for the humans who would follow them into space. Here again, Pavlov's research on the biological foundations of personality and use of dogs as models for human behaviour provided an important foundation. Like Pavlov, they identified different basic temperaments among their research subjects, dividing the candidates who made it through the initial tests into three groups: quiet dogs, more excitable dogs and 'sluggish' dogs. ${ }^{43}$ The most valuable animals belonged to the 'quiet' (spokoinyi) category. These dogs displayed a 'strong and well-balanced type of higher nervous activity' and adapted well to

42 Russell, op. cit. (41). Also see Stephen Pemberton, 'Canine technologies, model patients: the historical production of hemophiliac dogs in American biomedicine', in Schrepfer and Scranton, op. cit. (41), pp. 191-214.

43 Yazdovskii, op. cit. (17), p. 36. 


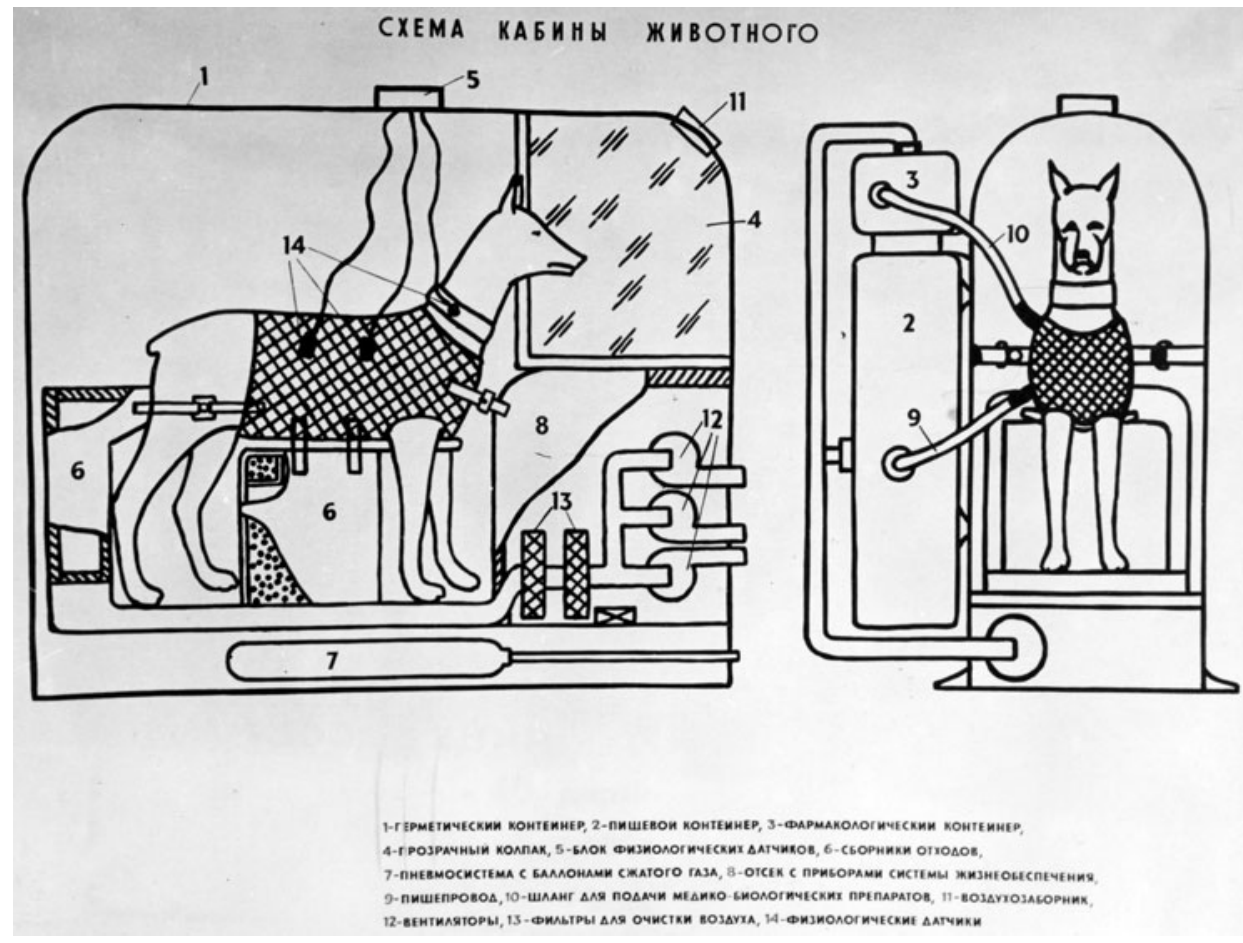

Figure 2. Schematic of the Sputnik 2 cabin with dog technology. The dog's suit provided an interface with the life-support, monitoring and restraint systems in the cabin. Source: RGANTD fond 35, opis' 3 , delo 57.

extensive experiments. ${ }^{44}$ Nearly all of the satellite (orbital-flight) dogs fell into this group, including Laika, Belka, Strelka, 'our favorite' Lisichka, and Zvezdochka. In Pavlovian parlance, which had some similarities to classical Hippocratic-Galenian temperament types, these dogs would be characterized as having a 'balanced' disposition that was 'slow and phlegmatic'. ${ }^{45}$ To us they would seem to be calm, friendly, evenkeeled dogs who were not easily frightened. The second group of dogs had higher energy levels and were more easily excited. They learned quickly and were better suited to the shorter experiments that prepared dogs for vertical flights. Again using Pavlov's (admittedly confusing) typology, the researchers identified these dogs as having strong and balanced dispositions, but with characteristics that made them more mobile and sanguine. The final group of dogs were extremely placid creatures, labelled 'sluggish' (vialyilsonlivyi) by the researchers.

44 Animals, Pioneers of Outer Space: Physiological Experiments with Animals Flying in Geophysical Rockets, Biological Studies during Space Flights, Moscow: Novosti Press Agency Publishing House, 1965.

45 Todes, op. cit. (36), p. 508; Miklósi, op. cit. (3), p. 222, Gerd and Gurovskii, op. cit. (21), p. 27, pp. 47-48. 
In their interactions with the dogs researchers perpetuated one of the most distinctive qualities of Pavlov's practice: the tension between his stance as a neutral scientist investigating indifferent natural material and his involved, even sentimental, attachment to experimental subjects. Since Pavlov had used dogs to investigate the workings of human behaviour and personality, assumptions about the similarities between dogs and humans came easily to the space researchers, while the dog's role as a 'friend' of humanity and 'servant' of science validated its use in the laboratory and on the launch pad. Indeed publicity about the space dogs sometimes referenced the 'trust' humans had invested in the dogs chosen to perform this 'service to humanity' by citing Pavlov's claim that 'the dog, thanks to its long attraction to humans, and its quickwitted patience and obedience, serves the experimenter with a certain joy ... sometimes for its whole life'. ${ }^{46}$ Looking back at the dog programme near the end of his own life, Gazenko insisted that the researchers saw the dogs as colleagues and friends: 'No one saw them as "just dogs". '47 The contradiction between regarding dogs as helpmates, servants and friends and the compulsion to 'sacrifice' them for science had complex implications for the relationships between researchers and the dogs. ${ }^{48}$

Dogs were categorized and selected by character type, but also recognized and valued for their individuality and uniqueness. They had names, and how they behaved outside the laboratory - how much they slept, whether they liked to play with their kennelmates, how independent they were on walks, their preferences for people and food, and so on was all noted as additional evidence of an individual dog's personality. Having an extensive battery of baseline data about a dog's 'normal' habits allowed researchers to assess the impact of stress after particularly gruelling experiments or flights even when biological markers appeared normal. Gazenko and Gerd considered behaviour an 'extremely sensitive indicator' of overall well-being. ${ }^{49}$ And they found that the speed with which bodily functions normalized after flight (cardiovascular as well as behavioural) depended on the individual traits of specific animals. ${ }^{50}$ Individual characteristics and experiences shaped the agency of each dog.

The most-travelled rocket dog, who had been called Kusachka ('Biter'), was renamed Otvazhnaia ('Brave One') after her fourth flight in $1959 .{ }^{51}$ Researchers deemed her 'a professional cosmonaut', and noted that she had responded more favourably (with less stress and fewer after-effects) to each flight. ${ }^{52}$ After her next flight all again

46 Daniel P. Todes, Pavlov's Physiology Factory: Experimentation, Interpretation, Laboratory Enterprise, Baltimore: Johns Hopkins University Press, 2002, pp. 123-152; Strel'chuk and Gartsshtein, op. cit. (27); Gerd and Gurovskii, op. cit. (21), p. 34.

47 Gazenko, op. cit. (15).

48 The Soviets are not alone here. See Carbone, op. cit. (8), p. 84, on the contradictory social-contract ethic informing use of dogs in scientific research more generally.

49 Gerd and Gurovskii, op. cit. (21), p. 28; Yazdovskii, op. cit. (17), p. 36. On contemporary recognition of the role behaviour plays in scientific outcomes see Joseph P. Garner, 'Stereotypes and other abnormal repetitive behaviors: potential impact on validity, reliability, and replicability of scientific outcomes', ILAR Journal (2005) 46, pp. 106-117.

50 Kas'ian, op. cit. (19), p. 267.

51 A. Golikov and K. Ivanov, 'Piat' poletov “Otvazhnoi”', Ogonek (10 July 1960) 28, p. 30.

52 Kas'ian, op. cit. (19), p. 267. 
seemed well. She had not been injured and her bloodwork and other tests were normal. But the dog, who had always seemed unfazed after returning from space, behaved differently this time. Normally very active and confident, Otvazhnaia was now reluctant to leave her kennel for her daily walk and did not run around and play with the other dogs, preferring to trot along beside the woman supervising the exercise period. ${ }^{53}$ Only gradually did she become the confident dog she had been before the fifth flight. The scientists recognized that there would be some carry-over in the nature of the effects of flight when people took the dogs' place, but counted on the 'strong will' of humans to at least partially offset the sometimes debilitating changes they observed in the dogs. ${ }^{54}$

While Yazdovskii and Gazenko embraced many of Pavlov's methods to test the dogs' resilience, develop profiles of their personality and modify their behaviour, we come here to a crucial difference between them. In his quest to understand psychiatric abnormalities, Pavlov set out to make dogs neurotic, and even break them completely. ${ }^{55} \mathrm{He}$ did this by first conditioning the animal to associate a negative stimulus such as an electric shock with a particular signal, and then introducing an element of randomness into the setting that made it impossible for the dog to either anticipate or escape the painful stimulus. ${ }^{56}$ Yazdovskii and Gazenko, however, had different objectives. They did not want to break the dogs. Although trauma and death sometimes occurred, their goal was to identify animals who could endure environmental extremes and stresses and remain psychologically as well as physiologically intact.

Their evolving regime of testing and training had three integrated components. The first focused on testing the limits and adaptive capacities of a dog's exposure to the main environmental stresses associated with flight: excessive $g$ forces, vibration, noise, silence, isolation and prolonged confinement. They used catapulting sleds, centrifuges, vibration stands and isolation chambers for these experiments. They also tested the dogs in barometric chambers and subjected them to extremes of heat and cold. While researchers referred to tests of these kinds as 'training' (trenirovka), thinking about them as conditioning experiments would be more apt. Certainly for work on the centrifuge and vibration stand little was provided in the way of preparation. The dogs were strapped on and attached to the monitoring devices, spun and shaken accordingly, and then evaluated for their biological and behavioural response. Spikes in blood pressure and heart rate, terrified straining at the restraints during the experiment followed by utter exhaustion afterward, were par for the course. But in dogs who became flight candidates the extremity of the response abated with repeated exposure. ${ }^{57}$

The second aspect of the programme focused on developing specific shaped behaviours (what Pavlovians call conditional reflexes), such as pushing a lever in response to a particular signal (i.e. a light - not a bell) in order to receive a food reward. The

53 Gerd and Gurovskii, op. cit. (21), p. 30.

54 Gerd and Gurovskii, op. cit. (21), p. 99.

55 Miklósi, op. cit. (3), pp. 4-5; Todes, op. cit. (36), pp. 337-353, 494-509.

56 The effects of this traumatization were expressed in abject displays of learned helplessness, documented in grisly detail in Vsevolod Pudovkin's 1926 film The Mechanics of the Brain, at https://vimeo.com/20583313.

57 Gerd and Gurovskii, op. cit. (21), pp. 89-91. 
conditional reflex was, of course, a mainstay of Soviet behaviourism. Once the dogs performed the desired operations reliably in 'normal' circumstances, they were asked to repeat them after testing or flights. For the early vertical flights (the 1951 series), Yazdovskii's team found the dogs' ability to perform these behaviours soon after landing a very reassuring sign. It meant that experiencing the intensified $g$ forces, vibrations and weightlessness of the flight had not damaged the dogs. By extension, they could assume that the same would be true for human beings. Similarly, the deterioration of a dog's ability to perform its conditional reflexes after a long session in the centrifuge, or on returning from a flight, aroused concern in terms of the potential effects of these stressors on people. The scientists wanted to know if the damage was permanent and why some individuals showed more persistent negative effects than others. ${ }^{58}$

The third component of the training regimen involved adapting basic life activities such as eating and defecating to conditions that ran counter to a dog's natural behaviour. During orbital flights and the extensive ground experiments in small isolation chambers the dogs would need to take in food and liquid and get rid of bodily waste. They had to do so while confined and with their opportunities for movement severely constricted. Most importantly, they had to accommodate these environmental limitations without exhibiting stress. They had to behave 'normally' in incredibly abnormal conditions. Pavlov's method of associative learning was of little help here, and this is where the experience of Maria Gerd, the animal trainer from the Durov corner, came into play.

\section{What space dogs did}

For all of the complexities (and inconsistencies) of Pavlov's biologically oriented personality research, the belief that behaviour in animals and people was essentially a matter of stimulus and response and the interplay between the organism and its environment was always front and centre. In comparative psychology dogs were neural systems exemplifying learning processes, not representatives of a species with its own distinct behaviours and capacities. ${ }^{59}$ The methods of classical conditioning would serve to teach a dog to press a lever in response to a light in order to get a treat, but they would not convince dogs to spend a week restrained in a tiny hermetic cabin using a sanitation suit and be more or less content with their situation. Individual dogs had to identify strategies to meet the potentially devastating challenges presented by long-term sensory deprivation, restricted movement and loss of social interaction. Gerd was critical here because she had worked with animals in the circus and understood them as such. She recognized that what the researchers wanted contradicted the natural inclinations of the dogs, often profoundly, and developed a training programme that approached the extreme conditions of the space capsule with the dogs' capacities as dogs in mind. ${ }^{60}$

58 Gerd and Gurovskii, op. cit. (21), p. 126.

59 Horowitz and Hecht, op. cit. (11), pp. 201-202.

60 M.A. (Mariia Aleksandrovna) Gerd, Reaktsii i povedenie sobak v ekstremal'nyk usloviiakh, Moscow: Nauka, 1976. 
But the dogs themselves were even more significant. A fundamental premise of ethology, the study of species-specific behaviour, is that animals must be observed in their 'natural' habitat. The laboratory environment is highly 'unnatural' (obviously), but then again, dogs are uniquely 'unnatural' animals. Following Bruno Latour's assertion about sets of practices that characterize 'the modern', they might be considered hybrids of nature and culture that resist (or complicate) the quest for 'purification' that is, the creation and maintenance of distinct ontological zones between the human and the non-human. ${ }^{61}$ Twentieth-century ethologists generally avoided studying dogs because, as domesticates, they were considered 'artificial animals' (created by humans), and thus lacked a 'natural' habitat. ${ }^{62}$ Alexandra Horowitz finds evidence of ongoing conceptual ambiguity surrounding dogs in the disconnect between training methods that approach dogs as essentially wild animals (house wolves) and the popular penchant (at least in urbanized Western societies) for treating pet dogs as furry people. Representing a new generation of researchers who embrace the connections between the environments and social behaviour of humans and dogs, she suggests that we consider them 'animals with an asterisk'. ${ }^{63}$ The dog's natural environment varies over space, time and culture, but is always shared with and shaped by humans. ${ }^{64}$ Thanks to our long co-evolutionary history with them, they are pervasively implicated in human society and adept at reading human behaviour.

Before they came to the Institute of Aviation and Space Medicine, most of the space dogs, like the majority of the world's dogs, were not pets, but strays - young scavengers living on the fringes of Moscow society. Many of them had, however, started out as pets, and they all had to be well socialized to people in order to be kept in the programme. ${ }^{65}$ Like all dogs, they had an innate interest in human company - as a source of food, certainly, but also as the necessary component of the ecological niche where they could thrive. ${ }^{66}$

While we might not (ever) know what it is 'like' to be a dog, recent scientific research and our own experiences with dogs have much to say about dogs' social and cognitive capacities and what the world might look like from their perspective. ${ }^{67}$ Using Jakob von Uexküll's concept of the Umwelt - the subjective perspective of an organism - Horowitz cautions us to beware of the anthropomorphism that so pervades our understanding of dogs. She reminds us that unlike humans, who are profoundly visual, the dog's sensory experience is dominated by its nose. It uses its mouth and tongue to explore, taste and manipulate objects and other animals. Most significantly, in terms of canine agency,

61 Bruno Latour, We Have Never Been Modern, Cambridge, MA: Harvard University Press, 1993, p. 11.

62 Miklósi, op. cit. (3), p. 1.

63 Horowitz, op. cit. (3) p. 56.

64 Miklósi, op. cit. (3), p. 47.

65 For a partially fictionalized account of how a boy's companion became one of the rocket dogs see the children's book M. Baranova et al., Rags, Borya and the Rocket: A Tale of Homeless Dogs and How They Became Famous, Moscow: Progress Publishers, 1964.

66 Carbone, op. cit. (8) p. 83; Miklósi, op. cit. (3), pp. 165-200.

67 On the challenges of knowing the other see Thomas Nagel, 'What is it like to be a bat?', Philosophical Review (1974) 83, pp. 435-450. 
Horowitz's research documents the ways in which dogs are attuned to humans. ${ }^{68}$ Dogs know us by smell, appearance and behaviour. They watch us. They follow our gazes and our gestures. 'We are known by our dogs, probably far better than we know them.'69 They are adept at reading our body language. So adept that Horowitz characterizes them as 'canine anthropologists'. They also seek out and develop relationships with us: the bonding between people and dogs is a two-way street. ${ }^{70}$

With this in mind, reading between the lines of the behaviourist jargon and anthropomorphic rationales that researchers used to describe what the dogs did becomes somewhat easier. Gerd and Gurovskii emphasized that all of the dogs they worked with had a 'benevolent relationship [dobrozhelatel'noe otnoshenie] with many people'. ${ }^{71}$ They explained this in terms of the dogs' dependence on the experimenters, claiming that the dogs' small size made them need people more than large dogs did. More intriguingly, they posited that 'when a large number of various people concern themselves with a particular dog, man becomes a somewhat generalized stimulus for the animal' ${ }^{72}$ The dogs' desire to be with people even made them welcome the attentions of experimenters who subjected them to painful and stressful situations, such as sessions on the vibrostand. And although the dogs were 'friendly' with everyone, Gerd and Gurovskii thought each one really wanted a 'single master'. The famous Belka, for example, became very attached to a 'tall corpulent woman' at the institute, playing up to her, following her around, and ignoring other people when the woman was present. ${ }^{73}$

But where Gerd and Gurovskii saw dependence and 'generalized stimulus', an ethologist such as Horowitz might see communication and relationship building, and a historian might see canine agency in action. The dogs sought contact with people. They wanted interaction and got attention by engaging people in ways the people found compelling. They barked if they were caged and made physical contact - jumping up on people or rubbing against them, when they weren't.

Gerd and Gurovskii noted that when a researcher entered the vivarium, the dogs followed them with their eyes. The person had only to 'look in the animal's direction' and the dog would respond with a welcoming tail wag. 'You have only to pet this dog and she is yours completely.' 74 The gaze is the critical element in this interaction. Dogs, who rely more on scent and touch to communicate with conspecifics, know that eye contact is the cement of attention where humans are concerned. ${ }^{75}$

In their memoirs, human participants were generous in acknowledging the agency of individual dogs and how much the dogs collaborated with them. A few minutes before Belka and Strelka's flight, the scientists noticed that the indicator for Strelka's arterial pressure had vanished from the apparatus that monitored all of the physiological functions

68 Horowitz, op. cit. (3), especially pp. 13-32, 209-259.

69 Horowitz, op. cit. (3), p. 161.

70 Horowitz, op. cit. (3), pp. 161-175, 259-283.

71 Gerd and Gurovskii, op. cit. (21), p. 23.

72 Gerd and Gurovskii, op. cit. (21), p. 31.

73 Gerd and Gurovskii, op. cit. (21), p. 33.

74 Gerd and Gurovskii, op. cit. (21), p. 31.

75 Horowitz, op. cit. (3), pp. 143-144. 


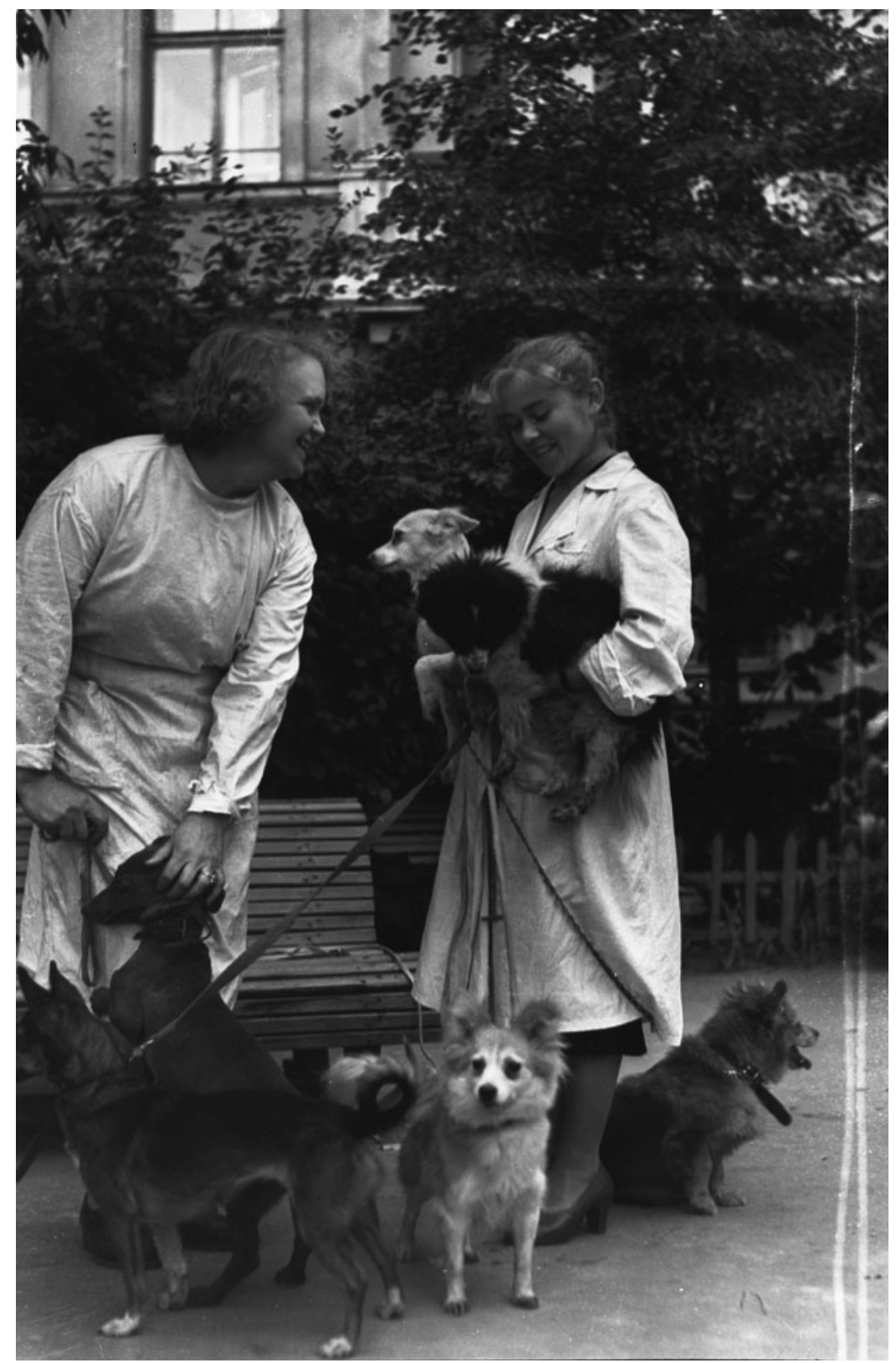

Figure 3. Space dogs interact with their handlers during a walk and photo-op. Source: RGANTD arkh. No 1-19562.

during flight. So close to launch, they had few options to repair the problem and no time to physically inspect the cabin. Then Roman Baevsky, who had helped develop the equipment (the KMA-1), noticed through the porthole that the case holding the cuff on Strelka's 
arterial fold had come loose. He opened the porthole but the dog was out of reach. Seeing Baevsky gesturing, Strelka not only crawled forward but turned her head so that he could reattach the cuff to the artery and secure it with a new pin. 'Strelka understood my request!' recalled Baevsky. ${ }^{76}$ By describing his effort to fix the monitoring equipment as a 'request' made to Strelka, Baevsky recognizes how connected the dog's agency is to his own. Her ability to understand and willingness to comply were essential to the success of his effort.

Baevsky's recollections of Lisichka, who in many ways was 'unlike her canine colleagues', are also telling. As part of the preparations to send Lisichka on an orbital flight in the spring of 1960, Baevsky had to implant electrodes under the dog's skin. He had not worked with dogs before and was a bit afraid of them. This was a reasonable fear, as the dogs associated him with painful procedures and sometimes tried to bite. But not Lisichka. Entering the room she wagged her tail and seemed to smile. Then 'she ran up to me on her own, lightly jumped up onto the examining table and lay on her right side, holding up her left paw for the implanting of the electrode'. ${ }^{77}$ She did not need to be restrained or muzzled. Baevsky could work on her alone, without a lab technician.

While Baevsky misreads the signs of submissive behaviour here - the low wagging tail, 'grin' and rolling over to expose the underbelly - he recognizes the dog's agency by acknowledging that she chose to behave in a particular way. Another incident brought the significance of Lisichka's attachment to him home even more powerfully. This time Baevsky was not present for the start of the procedure. Although she had a reputation for being very cooperative, this time she resisted with all her might, and two lab assistants could not strap her down. Baevsky was called in, and when Lisichka saw him she immediately submitted:

But she looked at me in a way that made me feel terrible. In her gaze I read offense, surprise and incomprehension all at the same time. The point was that I had a custom of talking to her and explaining what we were doing. The dog answered trust with trust. And now here, on the operating table, she turned to me for an explanation of what was going on. I asked the assistants to leave, and unfastened the dog, which alarmed our leader, Yazdovskii. Then I petted Lisichka, and told her that it was necessary and important that she behave quietly. I asked her to lie on her right side. The operation to implant the electrode went quickly. The dog did not move or twist. The surgeon was satisfied. ${ }^{78}$

'The dog answered trust with trust.' Despret's model of anthrozoogenesis highlights how researchers' beliefs about organisms shape interactions in the laboratory and create new identities. Baevsky's recollections of Lisichka suggest that dogs' expectations of people, and their ability to read them, were capacities that defined their agency. His description of his relationship with her also reveals her agency as a unique individual acting with purpose and expectations of other agents (humans). And as with the incident involving Strelka, his memories of Lisichka suggest that individual dogs identified themselves as suitable candidates for flight just as much as humans chose them.

The space dogs' agency worked in multiple registers. They demonstrated agency along the distributed and heterogeneous model proposed by ANT, especially where the interface

76 Kas'ian, op. cit. (19), pp. 271, 279.

77 Kas'ian, op. cit. (19), p. 276.

78 Kas'ian, op. cit. (19), p. 276. 
with technology and their status as 'compound technologies' or 'bio-technologies' is concerned. As experimental organisms manufactured and disciplined in the laboratory their aggregate agency contributed in vital ways to the success of the Promethean project of making space travel a reality for humans. But they also exemplify a more robust conception of animal agency as unique and named agents who served as essential partners in an enterprise not of their making. Following Haraway and Despret, I see these interactions between humans and dogs as constitutive. The activities that articulate relationships bring entities, subjects and objects into being. And in this analysis, the people and animals in the laboratory are implicated in each other's agency. They are both subjects and objects to each other because they are 'respons-able'. ${ }^{79}$

In some cases, the relationships that developed between dogs and researchers also provided a bridge to a more ordinary life after space travel. Anatoly Blagonravov adopted Tsygan ('Gypsy'), who had flown in the first rocket launch in July of 1951. And Gazenko shared his home for twelve years with Zhulka, one of the dogs who survived the ill-fated flight of December 1960. But for Lisichka - the dog that was 'everybody's favourite' - it was not to be. Along with Chaika ('Seagull'), Lisichka was supposed to be the first dog to return alive from orbital flight. The surgeries Baevsky performed on her were preparation for a much-anticipated launch of the R-7 prototype rocket on 28 July 1960 . Even the Chief Designer, Sergei Korolev, was attached to the little ginger-haired dog, interrupting the equipment testing one day to remove her from her harness. He held her close while she nuzzled him. 'I so want you to come back', murmured the famously gruff engineer. But the rocket exploded on the launch pad, killing both dogs and causing the mission to be excised from the record. ${ }^{80}$ The first successful orbital flight would come a month later, when Belka and Strelka became global celebrities.

The space dogs did what dogs do. They tried to survive by cultivating relationships with people. They responded to their caretakers' expectations that space flight was possible and to their more specific understandings of what dogs could do, must do, to help get the humans to space. The fact that they did not share the researcher's specific objectives or vision should not detract from the significance of what they did or the ways in which human agency is inextricably linked to that of dogs. All indications are that the dogs found the tests gruelling, terrifying and sometimes completely devastating. Some of them adapted, and many did not. But they were all actors, not just recipients of action. ${ }^{81}$ What the researchers viewed as 'training' and 'screening' worked for the dogs as a kind of self-selection. All of the dogs struggled to escape the first time they experienced the tight confinement cell. But those who responded more favourably stayed in the programme. They did not 'like' the centrifuge, the vibrostand and the isolation chamber, but they learned that these conditions were temporary and that their human partners would care for them afterward. In an era when we often speak of the need for resilience, the space dogs provide powerful witness to exactly that quality.

79 Haraway, When Species Meet, op. cit. (3) pp. 71-72; Despret, op. cit. (3), pp. 120-121.

80 Boris Chertok, Rockets and People, vol. 3, Hot Days of the Cold War, Washington, DC: NASA, p. 41.

81 Haraway, When Species Meet, op. cit. (3), p. 134. 